\section{Why are faces hard to recognize in photographic negative?*}

\author{
RICHARD J. PHILLIPS \\ University College London, London WC1E 6BT, England
}

Faces may be difficult to recognize in photographic negative simply because they contain a large range of grays, while printed words and geometric shapes, which contain no grays, are easy to recognize in negative. This explanation was partly tested in an experiment where Ss had to recognize positive and negative pictures of well-known people, both using normal monochrome photographs and using lith photographs in which all areas of gray were removed. Lith photographs were harder to recognize than normal photographs, but the difference between positive and negative was the same for lith pictures as for normal ones. This does not rule out an explanation in terms of grays, but it does put a major constraint on it.

There are at least three explanations for the difficulty we experience in recognizing a face in photographic negative. Negative faces appear to lose their expressions, and Galper (1970) suggests that this may be the root of the difficulty. To memorize expression is an unreliable way of recognizing a face. It changes from time to time. Nevertheless, Galper and Hochberg (1971) argue that expression characteristics do contribute to face recognition, and so the lack of expression in a negative face is a possible explanation.

A second explanation involves the role of shadow in face recognition. Shadow provides cues about the three-dimensional shape of a face. But in photographic negative, shadows are light areas that are hard to interpret, and this might make a face difficult to recognize. Bradshaw and Wallace (1971) studied the speed with which Ss could scan rows of Identi-kit faces looking for identical pairs. Surprisingly, they found no difference between positive and negative faces, both in the time taken to process critical features and in the false positive rate. Identi-kit faces contain less shadow than monochrome photographs and far less than many drawings and paintings. This lack of shadow could possibly explain Bradshaw and Wallace's results.

But there is another simple explanation. A monochrome photograph of a face contains a large range of grays as well as black and white. Patterns that we know are easy to recognize in negative (for example, printed words and geometric shapes) contain few grays or no grays at all. Sutherland (1971) has suggested that we may encode descriptions of visual

* Supported by a grant from the Science Research Council. My thanks to Ian Morin for his helpful criticism and to Jim Chambers for photographic advice. patterns in a way that makes it easy to negate a pattern that contains only black and white, but very difficult to negate when the description includes a large range of tones. It is possible that the difficulty with negative faces is simply due to the large range of grays that occurs in pictures of the human face.

This third explanation would be supported if the difficulty with negative faces disappears when using photographs without grays. By copying a photograph on lith film, it is possible to make a picture that contains only areas of black and white. All dark grays become black and all light grays become white. This experiment tests the recognition of well-known faces seen in positive and negative, both for normal photographs and for lith photographs.

Lith photographs will certainly be harder to recognize than normal the relative difference between positive and negative will be much greater for normal pictures than for lith ones.

\section{METHOD \\ Material}

The Ss were tested on 16 photographs of well-known men. All the pictures were full face or three-quarters face, they were against a black background, they were cropped at the neck to eliminate clothing, and they included no beards, moustaches, glasses or other obtrusive features. A pilot study was used to divide the pictures into four groups of roughly equal difficulty to English undergraduates. The four groups were (1) Harold Wilson, Tony Jacklin, Alfred Hitchcock, Ian Carmichael; (2) Edward Heath, Willy Brandt, Michael Parkinson, Charlie George; (3) Richard Nixon, Jeremy Thorpe, Bruce Forsyth, Richard Chamberlain; and (4) Winston Churchill, Jimmy photographs, but it is predicted that
Young, Roy Jenkins, Desmond Morris. Four monochrome slides were prepared for each face: a normal positive photograph, a normal negative photograph, a positive lith photograph, and a negative lith photograph. When projected, each face subtended an angle of about $15 \mathrm{deg}$ at the $S$ 's eyes.

\section{Design}

Each S saw 16 faces-4 under each condition. The four conditions were systematically varied with the four groups of faces so that any face was seen exactly four times under each condition. The four pictures in any condition were shown together but in a random order. The presentation order of the four conditions was also randomized.

\section{Procedure}

The Ss were 16 undergraduate students -14 male and 2 female. They were told that they would be shown some photographs of well-known men whom they had to identify. They were to write down the surname, or, if they could not think of a name, a brief description that uniquely identified the person would also be accepted. Ss pressed a button to indicate that they were ready for the next picture. A slide was blacked out after $15 \mathrm{sec}$ if the $S$ had not pressed the button before this time. recognized a maximum of four faces on any condition. Table 1 shows Ss' mean scores for the four conditions. As expected, there was a large difference between positive and negative for the normal photographs (Wilcoxon matched-pairs test, $T=0$, $\mathbf{N}=12, p<.01$ ). But there was as large a difference between positive and negative for the lith photographs ( $\mathrm{T}=4.5, \mathrm{~N}=14, \mathrm{p}<.01$ ), although these were predicted to be of similar difficulty. The difference in means for normal and lith pictures was 1.4 and 1.3, respectively. These are close enough to suggest that, in this experiment, the difficulty in recognizing negative photographs of faces occurs equally in normal and lith pictures.

Table 1

Mean Number of Faces Correctly Identified (Out of Four) in Each Condition

\begin{tabular}{lcc}
\hline \multicolumn{1}{c}{ Condition } & Mean & SD \\
\hline Normal Positive & 2.5 & 1.0 \\
Normal Negative & 1.1 & 0.8 \\
Lith Positive & 1.9 & 0.9 \\
Lith Negative & 0.6 & 0.5 \\
\hline
\end{tabular}




\section{DISCUSSION}

Pictures of well-known faces are hard to recognize in negative, whether or not they contain grays. This does not necessarily rule out the role of grays in making negative faces difficult. It is uncertain whether the brain makes the negative transformation on the stored description of a face or on the face that is being looked at in the photograph. A flexible visual system might allow either to happen. But if the negative transformation must be made on the stored description (which no doubt includes grays), then one would expect the same difficulty with a lith negative as with a normal negative.

It is possible that a similar experiment where unknown faces were learned and tested would show different results. However, well-known faces are easy to test, and one can be fairly sure that the faces have been learned in a way that is close to our normal experience.

The reason for negative faces' being difficult to recognize will not become clear until some of the other explanations have been tested. The explanations that have been discussed here are not entirely independent, and, of course, there may be more than a single factor operating to make negative photographs of faces difficult.

REFERENCES

BRADSHAW, J. L., \& WALLACE, G Models for the processing and identification of faces. Perception \& Psychophysies, 1971, 9, 443-448.

GALPER, R. E. Recognition of faces in photographic negative. Psychonomic Science, 1970, 19, 207-208.

GALPER, R. E., \& HOCHBERG, J Recognition memory for photographs of faces. American Journal of Psychology faces. American 84 . 351-354.

SUTHERLAND, N. S. Visual recognition of objects. Paper read at the British Psychological Society London Conference, 1971.

(Received for publication May 15, 1972.) 